\title{
EXPLORE
}

\section{Perancangan Aplikasi Berbasis Web Pada System Aeroponik untuk Monitoring Nutrisi Menggunakan Framework CodeIgniter}

\author{
Robby Yuli Endra, Ahmad Cucus, M. Aditya Wulandana S \\ Program Studi Informatika, Fakultas Ilmu Komputer \\ Universitas Bandar lampung \\ Bandar Lampung, Indonesia \\ robby.yuliendra@ubl.ac.id,ahmad.cucus@ubl.ac.id,m_aditya.15421014@student.ubl.ac.id
}

\begin{abstract}
Abstrak-Tujuan Penelitian ini adalah merancangan sistem pemiliharaan tanaman aeroponik yang dilakukan secara otomatisasi berbasis web, yang dilakukan sistem ini adalah memberikan nutrisi kepada tanaman secara otomatis serta membantu untuk monitoring tanaman aeroponik oleh petani. sistem aeroponik tersebut dapat digunakan otomatisasi dalam pengukuran dan pengontrolan pertumbuhan tanaman Dengan diterapkannya teknologi otomatisasi pada aeroponik yang dapat melakukan pengontrolan pada beberapa aspek seperti suhu air, tingkat keasaman dan kebasaan air biasa disebut $\mathrm{pH}$ (potensial Hidrogen), nutrisi dan perkembangan tanaman aeroponik. Dengan adanya Internet of Things sehingga dapat dengan mudah mengambil nilai nutrisi dari sensor EC(Electrical Conducticity) pada air aeroponik, kemudian data tersebut dikirimkan ke server. Data hasil monitoring yang sudah terkirim ke server kemudian ditampilkan di website sebagai informasi tanaman aeroponik.
\end{abstract}

Keyword : Internet of Things, Aeroponik, Electrical Conducticity, Ph

\section{Pendahuluan}

Sebagian besar penduduk Indonesia hidup dari hasil bercocok tanam dan bertani, karena itu Indonesia menjadi negara agraris. pertanian berperan penting untuk meningkatkan kesejateraan dan kehidupan penduduk Indonesia [1]. Tetapi keadaan saat ini lahan di Indonesia semakin sempit, terutama di wilayah perkotaan. Tidak sedikit penduduk kota yang memiliki minat bercocok tanam. Namun dengan kondisi lahan yang semakin sempit dan keterbatasan waktu yang dimiliki membuat penduduk perkotaan mengurungkan niatnya untuk bercocok tanam. Dan selain itu kebutuhan akan sayuran oraganik sangat tinggi satu Solusi untuk mengatasi masalah tersebut digunakanlah sistem hidroponik.

Perubahan zaman yang dinamis, khususnya dibidang teknologi komunikasi dan informasi tidak dapat dielakan oleh siapa pun. Dimana saat ini masuk di era revolusi industri 4.0 yang menuntut setiap manusia untuk melakukan perubahan dinamis dalam melakukan kegiatan di kehidupan sehari-hari[2]. Sistem ini menerapkan teknologi informasi pada teknik pertanian perkotaan yang memanfaatkan air sebagai media tanam. Aplikasi teknologi digunakan untuk membantu manusia dalam mengendalikan, menjaga stabilitas kadar air yang dibutuhkan oleh tanaman agar berkembang dengan baik [3]. Hidroponik memiliki beberapa jenis salah satunya yaitu Aeroponik. Dengan menggunakan metode penyemprotan nutrisi lewat udara, aeroponik kini menjadi pilihan dari bagian hidroponik. Aeroponik merupakan salah satu tipe dari hidroponik karena air yang berisi larutan hara disemburkan dalam bentuk kabut hingga mengenai akar tanaman.

Peningkatan kebutuhan manusia yang diiringi dengan perkembangan teknologi dan ilmu pengetahuan yang sangat pesat, membuat manusia ingin menciptakan sesuatu serba otomatis. Otomatisasi sistem sekarang ini merupakan hal yang sangat diperlukan pada kehidupan sehari-hari. Otomatisasi sekarang ini bukan hanya sebagai pengganti atau meringankan aktifitas atau pekerjaan manusia, tetapi lebih kepada efesiensi hasil dari proses sistem otomatisasi tersebut.

Untuk membantu sistem aeroponik tersebut dapat digunakan otomatisasi dalam pengukuran dan pengontrolan pertumbuhan tanaman dengan menggunakan Mikrokontroler. Mikrokontroler adalah otak dari suatu sistem elektronika seperti halnya mikroprosesor sebagai otak komputer. Selain 
mikrokontroler dibutuhkan pengembangan teknologi seperti Io'T (Internet of Things). Io'T saat ini menjadi bidang populer pada penelitian semenjak berkembang teknologi ke revolusi industri 4.0, tentunya berkembang iot harus didukung dengan berkembangnya internet dan media komunikasi yang lain. semakin banyak kebutuhan manusia akan teknologi, maka semakin banyak hasil-hasil penelitian yang dilakukan dan pada masa depan akan banyak hadir. Internet of things merupakan hasil dari pemikiran manusia akan teknologi yang menggabungkan banyak alat misalnya sensor sebagai media input, radio frequency identification (RFID), sensor jaringan tanpa kabel serta objek-objek lain yang memungkinkan user atau manusia dapat berkomunikasi serta berinteraksi dengan semua alat yang terhubung dengan internet.. Dalam penerapannya Io'T dapat mengidentifikasi, menemukan, melacak, memantau objek dan memicu event terkait secara otomatis dan real time[4].

Dengan diterapkannya teknologi otomatisasi pada aeroponik yang dapat melakukan pengontrolan pada beberapa aspek seperti suhu air, tingkat keasaman dan kebasaan air biasa disebut $\mathrm{pH}$ (potensial Hidrogen), nutrisi dan perkembangan tanaman aeroponik. Adanya IoT yang dapat mengambil nilai nutrisi dari sensor EC(Electrical Conducticity) pada air aeroponik kemudian data tersebut dikirimkan ke server. Data hasil monitoring yang sudah terkirim ke server kemudian ditampilkan di website sebagai informasi tanaman aeroponik. Sehingga pemilik aeroponik sudah tidak perlu lagi melakukan pengontrolan secara manual.

Data ketentuan tanaman yang ada di aeroponik semua disimpan di server sehingga pemilik aeroponik dapat mengetahui apakah nutrisi tanaman pada air aeroponik sudah sesuai dengan standar ketentuan. Pengontrolan tanaman menjadi lebih mudah dengan adanya implementasi automasi untuk kontroling aeroponik.

Dengan adanya teknologi tersebut Petani dapat melakukan monitoring dan kontroling kandungan air secara otomatis dengan sistem yang dirancang.

\section{Dasar Teori}

\section{A. Penelitian Terkait}

Pada penelitian yang berjudul "Hydroponics, Aeroponic and Aquaponic as Compared with Conventional Farming" yang ditulis oleh R \& D Division, AlAin, dkk. Pada American Scientific Research Journal for Engineering, Technology, and Sciences, pada tahu 2017 bahwa Hidroponik adalah seni pertanian yang tanaman tumbuh tidak menggunakan tanah secara langsung tanaman tersebut tidak kotor. Atau secara umum konsep dari hidroponik adalah menanam tanaman dengan media tertentu dengan menggunakan aliran air. Pada aeroponik tanaman tidak diberi media untuk tumbuh akar melainkan dibiarkan terbuka dan menggantung pada suatu tempat yang telah dijaga kelembabannya. Banyak penelitian yang membahas tentang hidroponik, aeroponik dan aquaponik dengan bentuk komersial dan itu merupakan potensi yang positif. Serta peran teknologi tidak dapat dielakan lagi dan Sistem pertanian pertanian itu bisa sajasatu alternatif berkelanjutan untuk menyediakan berbagai jenis produk yang membutuhkan lebih sedikit air, lebih sedikit pupuk dan lebih sedikitruang yang akan meningkatkan hasil per satuan luas. Keuntungan utama dari sistem budidaya modern tersebut adalah kebutuhan lahan yang berkurag serta kebutuhan bahan kimia yang sangat berbahaya bagi manusia[5].

Pada Penelitian lain yang berjudul "Pemanfaatan Lahan Dengan Menggunakan Sistem Hidroponik" yang ditulis oleh Roidah Syamsu bahwa Pertanian merupakan sektor yang sangat penting bagi masyarakat Indonesia. Sektor pertanian sebagai salah satu sumber penghasilan bagi masyarakat, karena sebagian kawasan Indonesia merupakan lahan pertanian. Para petani biasanya menggunakan tanah untuk media. Melihat banyaknya lahan yang tidak dipakai oleh masyarakat untuk lahan pertanian, maka saat ini dilakukan pengembangan dalam bidang pertanian. Saat ini, kemajuan teknologi sangat berkembang dengan cepat, sehingga masyarakat khususnya petani dapat memanfaatkan kemajuan teknologi tersebut untuk mendukung pekerjaaan dan menghasilkan keuntungan yang optimal dari kegiatan yang dilakukan mereka.Untuk petani, teknologi yang saat ini dapat ditawarkan adalah hidroponik.kenapa hidroponik alasannya adalah semakin sedikitnya lahan pertanian karena lahan-lahan tersebut di kembangkan untuk bidang industri, properti atau industri lainnya. karena hal tersebut bidang pertanian yang masih menggunakan cara lama semakin hari semakin tidak dapat bersaing karena salah satu alasan yaitu harga lahan yang semakin tinggi. dengan menggunakan hidroponik diharapkan dapat menjadi alternatif ke petani untuk dapat bertani malaupun lahan yang dimiliki makin sedikit. hidroponik merupakan cara bercocok tanam tanpa menggunakan media tanah, hidroponik biasanya menggunakan batu apung, kerikil, pasir, sabut kelapa, atau busa dan potongan kayu.untuk mengalikan atau menambah nutrisi pada tanamam, mengaliri air dan oksisgen. tidak memerlukan tanah sebagai media perantara.[6]

\section{B. Aeroponic System}

Aeroponik berasal dari kata aero yang berarti udara dan ponus yang berarti daya. Aeroponik adalah sebuah teknik bertanam dengan cara menggantung akar tanaman tersebut di udara dan tumbuh dilingkungan lembab tanpa tanah, Karena akarnya digantungkan di udara, dan tidak memerlukan tanah, maka memungkinkan teknik ini untuk dilakukan hampir di mana saja [7]. Aeroponik merupakan salah satu media tanam tanpa menggunakan tanah, tetapi hanya unsur air atau larutan air yang disemburkan dalam bentuk kabut hingga mengenai akar tanaman. Jika pada teknik bertanam hidroponik larutan nutrisi untuk 
tanaman disirkulasikan dengan cara mengalirkannya, pada teknik aeroponik larutan nutrisi disemprotkan dalam bentuk kabut hingga mengenai akar tanaman. Performa sistem bercocok tanam aeroponik berpotensi untuk melebihi metode konvensional. Secara umum keuntungan sistem aeroponik dibandingkan dengan sistem budidaya lain, diantaranya: 1) menggunakan jauh lebih sedikit air; 2) memberikan ketersediaan air yang seragam bagi tanaman sepanjang tahun; 3) memudahkan pengamatan umbi dan pemanenan umbi lebih nyaman dan bersih; 4) mengoptimalkan aerasi pada akar; 5) memungkinkan produksi intensif dalam area yang terbatas[7]. Teknik hidroponik ini memungkinkan pemilik tanaman memperoleh hasil yang baik dan tercepat dibandingkan sistem hidroponik lainnya. Hal ini disebabkan oleh larutan nutrisi yang diberikan berbentuk kabut langsung masuk ke akar, sehingga tanaman lebih mudah menyerap nutrisi yang banyak mengandung oksigen.

Manfaat Penanaman Aeroponik (1)Tanaman dapat mudah di tanam dengan lahan yang tidak beraturan (2)Tanaman ini menghasilkan produksi lebih tinggi (3)Tanaman ini sangat tahan dan kuat terhadap serangan hama dan penyakit. (4)Tanaman ini dapat berbuah tidak tergantung musiman. (5)Buah yang di tanam yang berkualitas tinggi (6)Tanaman media ini juga termasuk teknologi menengah (7)Jangka panen lebih cepat
(8)Tanaman juga bisa di lakukan tanpa pengelolahan lahan.

\section{CodeIgniter}

Codeigniter adalah salah satu jenis kerangka kerja atau frame work untuk mengembangkan aplikasi berbasis web. Ci merupakan framework yang open source sehingga dapat memudahkan user untuk membuat Bahasa pemograma php yang dinamis. Keuntungan serta tujuan mengembangkan aplikasi menggunakan Codeigniter adalah untuk membantu developer untuk membuat aplikasi lebih cepat daripada menulis semua source code dari awal dan Codeigniter menyediakan banyak jenis library yang dapat mempermudah dalam pembuatan dan mengembangkan. Codeigniter diluncurkan ke kalayak umum pada tanggal 28 Februari 2006. Codeigniter dibangun dan dikembangkan menggunakan konsep Model-View-Controiller (MVC). Dalam Codeigniter, browser berinteraksi dan berkomunikasi melalui controller. Controller yang akan menerima dan membalas semua request dari browser. Ketika controller membutuhkan data, maka controller akan meminta ke Model. Sedangkan untuk tampilan ke user akan ditangani oleh View. Jadi otak dari aplikasi ada di controller, muka aplikasi ada di viewed an data berada di model [8]. CodeIgniter pertamakali dikembangkan pada tahun 2006 oleh Rick Ellis. Dengan logo api yang menyala, CodeIgniter dengan cepat "membakar" semangat para web developer untuk mengembangkan web dinamis dengan cepat dan mudah menggunakan framework PHP yang satu ini.

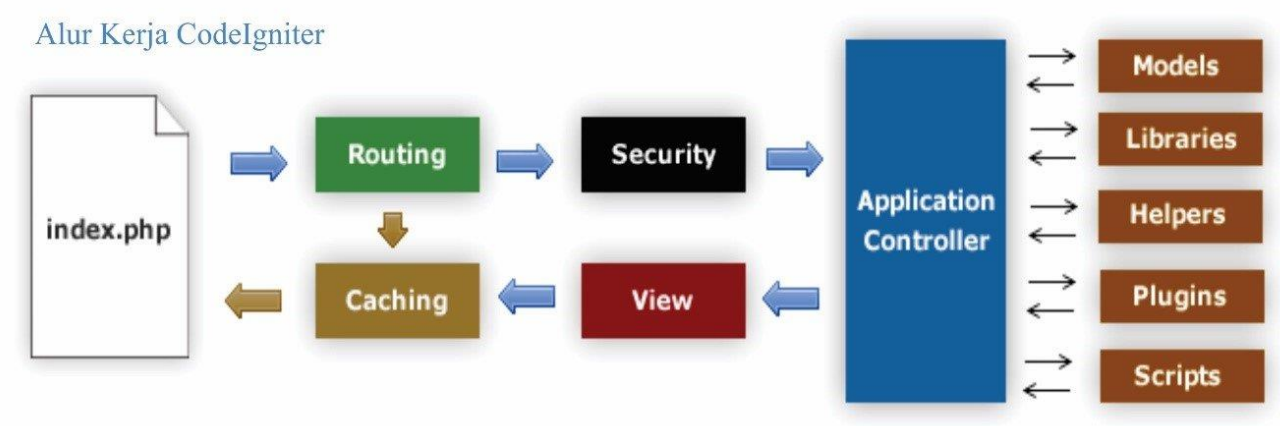

Gambar 1. Alur Kerja Framework CodeIgniter

\section{Metodologi}

Pada penelelitian ini mengacu pada konsep penelitian terapan[9] (applied research) yang bertujuan untuk memberikan solusi dibidang pertanian dengan menggunakan teknologi sebagai media dan alat bantu.

\section{A. Metode Pengumpulan Data}

Metode yang digunakan dalam pengumpulan dalam penelitian ini adalah dengan melakukan Studi Pustaka (Library Research) dan Studi Lapangan (Field Research).

\section{Studi Pustaka (Library Research)}

Pada penelitian ini studi pustaka dilakukan dengan mengumpulkan literature seperti buku-buku. E-books, jurnal-jurnal dan hasil penelitian lain yang bertemakan tentang aeroponik, hidroponik, Internet of Things, Framework CodeIgniter dan terkait dengan penelitian ini.

\section{Studi Lapangan (Field Research)}

Studi lapangan yang dilakukan dengan mengadakan penelitian secara langsung pada objek yang akan diteliti, Adapun metode yang dilakukan dalam studi lapangan adalah sebagai berikut :

a. Kepustakaan

Untuk mendukung penelitian ini dibutuhkan literature yang sudah dijelaskan pada poin 1 studi pustaka

b. Observasi

Pada tahap ini, peneliti langsung terjun kelapangan untuk mengamati proses pengembangan sistem, konfigurasi data dan hal-hal terkait dengan penelitian. 


\section{B. Analisa Kebutuhan Fungsional}

Analisis kebutuhan fungsional dilakukan untuk mengetahui spesifikasi fungsi yang mampu dilakukan oleh sistem. Analisis kebutuhan adalah kebutuhan yang berasal dari pemangku kepentingan (Stakeholders) termasuk fungsi dan fitur dari sebuah sistem. Kebutuhan fungsional juga berisi informasi-informasi apa saja yang harus ada dan dihasilkan oleh sistem.

1. Sistem digunakan sebagai media pengontrolan pada tanaman aeroponik, membantu proses otomatisasi dan monitoring data tanaman secara online yang dapat membantu bagi pengguna.

2. Sistem harus memberikan informasi data mengenai pertumbuhan tanaman aeroponik secara online.

\section{Analisa Kebutuhan Non-Fungsional}

Analisa kebutuhan non fungsional dilakukan untuk mengetahui spesifikasi kebutuhan untuk sistem. Spesifikasi kebutuhan melibatkan analisis perangkat keras/hardware, analisis perangkat lunak/software, analisis pengguna/user.

\section{Analisis Perangkat Keras (Hardware)}

Adapun kebutuhan perangkat keras (hardware) sistem tersebut adalah sebagai berikut (1)Processor (2)Memory (3)Ruang Harddisk (4)Monitor (5)Keyboard \& Mouse

2. Analisa Kebutuhan Perangkat Lunak (software)

Keberadaan perangkat lunak sangatlah penting karena perangkat lunak lunak (software) merupakan suatu alat yang digunakan dalam pembuatan sebuah sistem. Namun, perangkat lunak tidak dapat berdiri sendiri tanpa adanya perangkat keras (hardware), karena keduanya tidak dapat berfungsi sendiri-sendiri. Maka pada penelitian ini penulis menggunakan beberapa perangkat lunak (Software) seperti berikut: (1)Sistem operasi Windows 7 (64-bit) (2)Php Storm digunakan sebagai tools untuk membangun aplikasi (3)XAMPP for windows berfungsi sebagai server yang berdiri sendiri (4)PHP bahasa pemrograman yang digunakan untuk membangun aplikasi (5)MySql sebagai perangkat lunak untuk create database (6)Framework CodeIgniter yang digunakan untuk membangun aplikasi (7)Google Chrome untuk akses localhost.

\section{Perancangan Penelitian}

Rancangan penelitian dibuat dalam melakukan penelitian agar pelaksanaannya dapat berjalan secara benar, sistematis, baik, dan lancar. Oleh karenanya, rancangan penelitian mempunyai manfaat yang besar bagi kelancaran sebuah penelitian. Dengan rancangan penelitian, seorang peneliti mampu mengambil sikap dan keputusan yang tepat dalam mengatasi masalah penelitian.

Rancangan penelitian ini diawali dengan mengumpulkan semua data yang terkait dengan penelitian, kemudian melakukan design arsitektur sistem dari sistem yang dikembangkan.

\section{E. Arsitektur Perancangan Sistem Aeroponik}

Komponen-komponen yang menunjang untuk Aeroponik sebelum dibangun dan dirakit agar saling terhubung satu sama lain dibuat dalam bentuk simulasi. Untuk menemukan komponen fisik yang tepat dari sebuah struktur fisik. Simulasi tersebut dibuat dalam bentuk arsitektur perancangan. Arsitektur perancangan sistem hidroponik dapat dilihat pada gambar 3.1 dibawah ini.

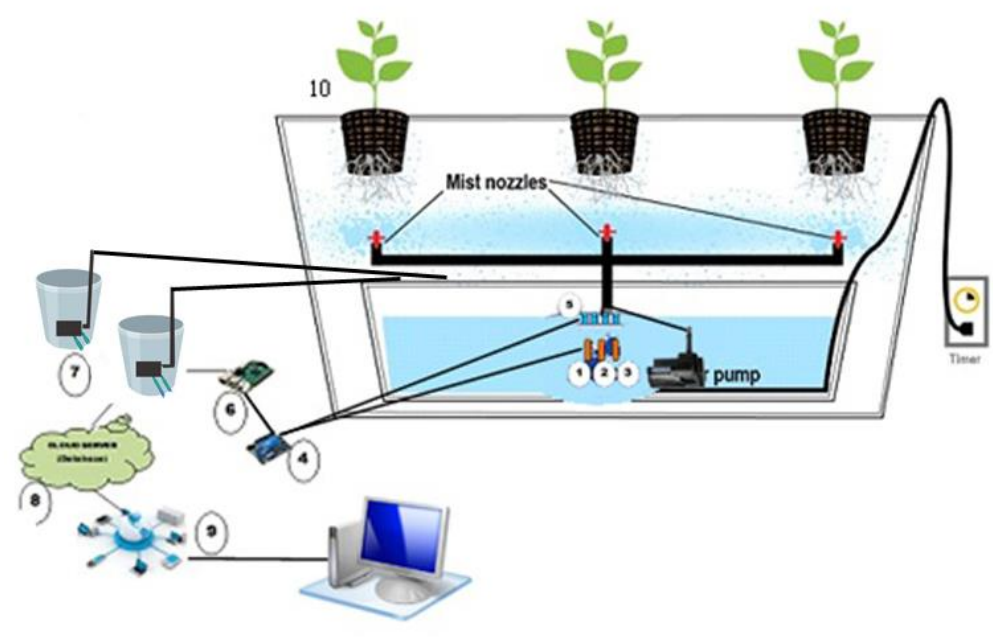

Gambar 2. Arsitektur Perancangan

Dengan keterangan perangkat sebagai berikut : (1)Sensor $E C$ mengambil nilai nutrisi dan mengirimkan inputan berupa nilai nutrisi. (2) Sensor $p H$ mengambil nilai keasaman air dan mengirimkan inputan berupa nilai $\mathrm{pH}$ (3) Sensor DHT11 mengambil nilai temperatur pada udara dan mengirimkan inputan berupa nilai suhu dan kelembapan. (4)Mikrokontroller yang digunakan untuk membaca dan mengambil inputan dari sensor, dengan jenis mikrokontroller yang digunakan Arduino Uno (5)Source Code yang dipakai untuk mengirimkan data sensor dari mikrokontroller ke webdijalankan di mini komputer yaitu Nodemcu. (6)Data yang sudah di pilah dikirim ke server (7)Wadah nutrisi dan PH berikut pompa bertugas mengaliri nutisi atau ph apabila mendapat perintah bahwa 
kandungan nutrisi atau ph dalam wadah utama kurang (8) Source Code yang dipakai untuk mengirimkan data sensor dari mikerokontroller ke webdijalankan di mini komputer yaitu Nodemcu. (9)Data yang sudah di pilah dikirim ke server. (10)Website menampilkan request user dan menampilkan informasi data sensor yang ditampung di server.

\section{Hasil dan Pembahasan}

Aplikasi sistem monitoring nutrisi berbasis web ini dikembangkan dengan menggunakan internet of things(IoT) pada automatisasi Aeroponik, hal tersebut yang menjadi referensi untuk peneliti dalam mengembangkan website ini. Sistem ini dikembangkan untuk memudahkan para petani untuk mengontrol nutrisi pada tanaman dengan menggunakan smartphone dan peangksesan halaman pun menggunakan web browser, semua informasi secara otomatis ada didalam dashboard website ini.

Dari hasil penelitian yang telah dilakukan, bahwa aplikasi monitoring nutrisi ini dapat memonitoring dan dapat membantu petani dengan teknologi.

\section{A. Alur Kerja Sistem}

Sistem kontrol berbasis web pada automatisasi Aeroponik. ini dirancang hanya memiliki satu pengguna saja, dimana pengguna sebagai admin utama dalam sistem ini. Hal pertama yang harus dilakukan oleh pengguna untk menggunakan sistem ini yaitu dengan mengakses alamat berikut ini https://teknokubator.com yang dapat diakses melalui komputer ataupun smartphone dengan menggunakan browser masing masing perangkat. Ketika pertama mengakases alamat web tersebut pengguna diharuskan untuk memasukan username dan password yang telah dibuat sebelumnya dihalaman login ini. Jika pengguna berhasil login maka akan diteruskan kehalaman dashboard dimana dihalaman ini pengguna dapat memonitor kondisi suhu, kelembapan, Nutrisi, $\mathrm{Ph}$ pada aeroponik system.

\section{B. Antar Muka}

Perancangan aplikasi sistem kontrol bebasi web pada automatisasi Aeroponik dengan menerapkan konsep internet of things yaitu sebagai sistem yang dapat memonitor kondisi suhu, kelembapan, nutrisi dan ph pada aeroponik system. Berikut adalah beberapa tampilan antar pengguna untuk berinteraksi dengan aplikasi sistem kontrol berbasis web.

\section{Tampilan Menu Login}

Alur dari halaman login ini adalah pengguna memasuk kan username dan password di kolom yang tersedia, jika username dan password salah maka akan kembali sekai lagi kehalaman login ini dan akan muncul informasi username atau password salah dan pengguna harus memasukkan username dan password kembali. Jika username dan password benar maka pengguna langsung akan masuk ke halaman dashboard.

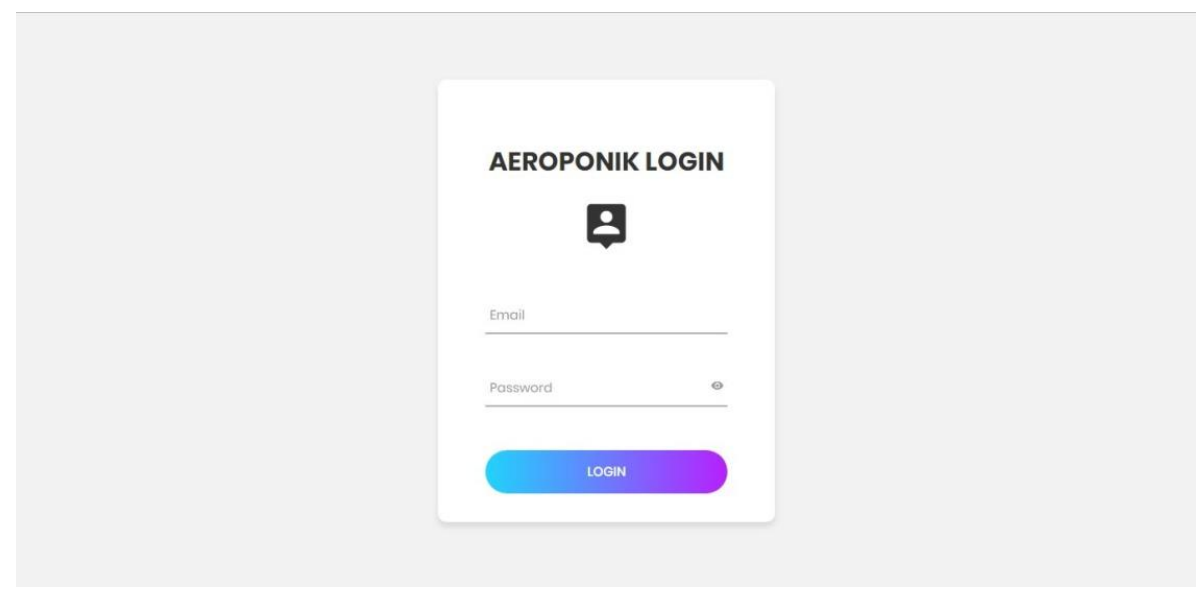

Gambar 3. Tampilan Halaman Login

\section{Tampilan Menu Utama/Dashboard}

Menu Utama atau Main Menu dalam aplikasi mempunyai peranan layaknya terminal atau pintu utama untuk mengakses form-form dalam suatu aplikasi. Main Menu itu sendiri adalah form yang berisi link / akses ke form-form lainnya. Menu utama ini terdiri dari menu- menu antara lain menu tabel tanaman, user, calender dan logout.

Dalam menu utama terdapat informasi yang melihatkan kondisi suhu, kelembapan, EC dan PH pada aeroponik system 


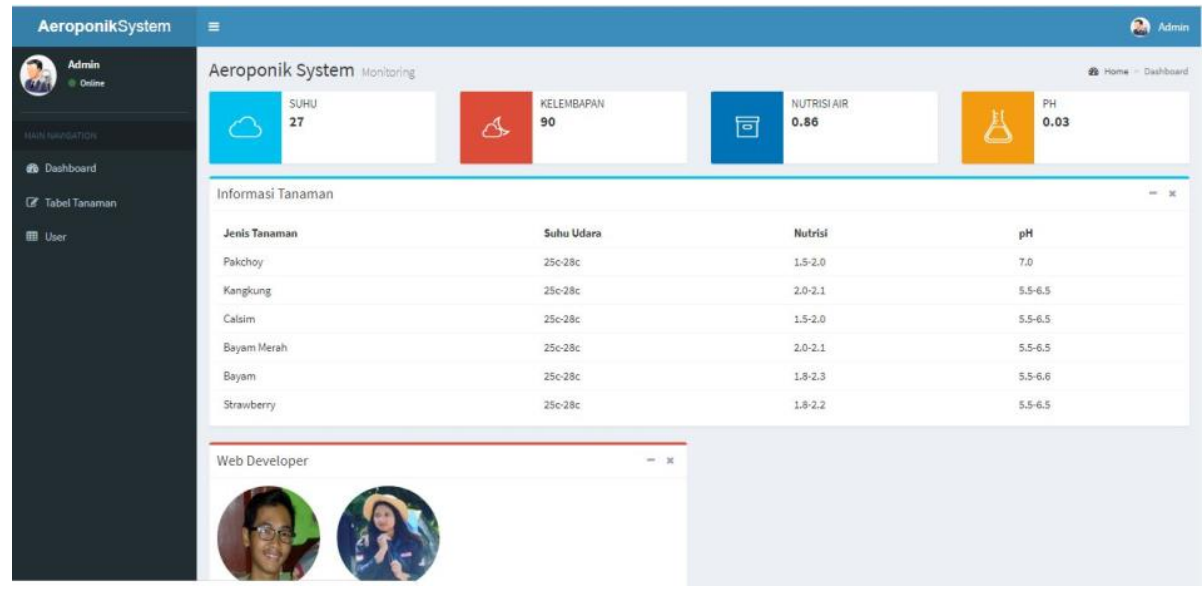

Gambar 4. Tampilan Halaman Dashboard

Tampilan Menu Tabel Tanaman

ada menu tabel ini terdapat data data kadar ec ph pada tanaman tanaman. Data tanaman ini ditampilkan dalam bentuk tabel dengan keterangan Jenis Tanaman, suhu udara, PH dan EC.

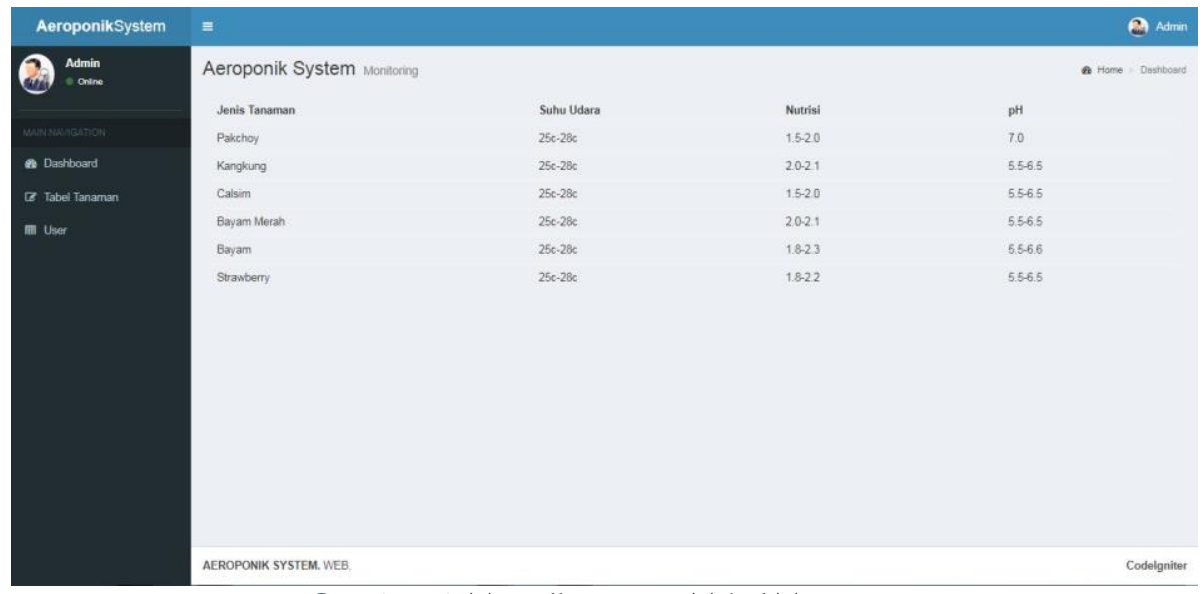

Gambar 5. Tampilan Menu Tabel Tanaman

\section{Rangkaian Skematik}

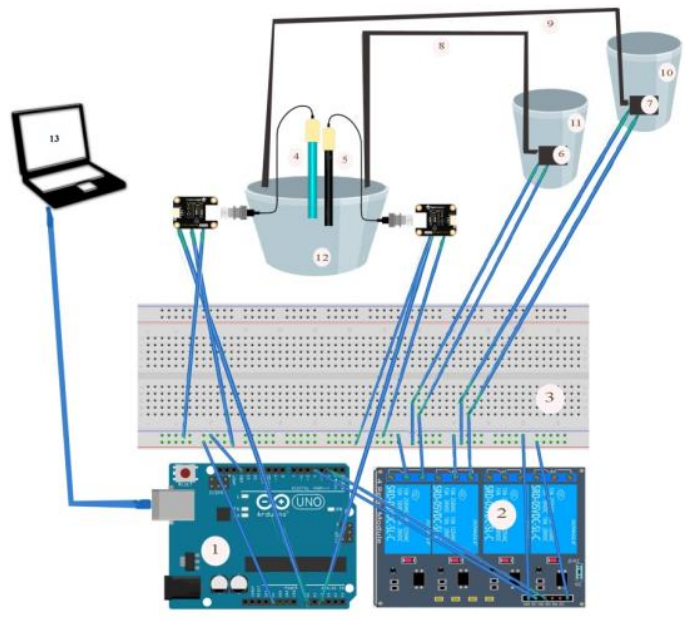

Keterangan pada gambar :

Gambar 6. Rangkaian Schematik

1. Arduino $=$ Mikrokontroller untuk menjalankan semua alat dan sensor
2. Rellay pompa

3. Board = Sebagai papan tambahan untuk kabel jumper arduino

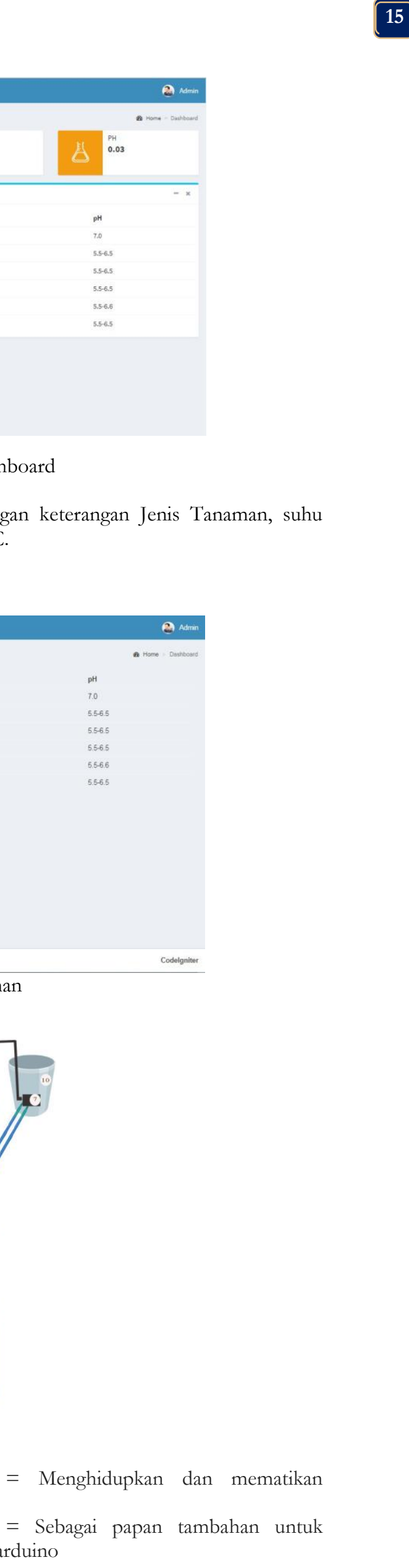


4. Sensor EC= Mendeteksi Nilai EC / Nutrisi

5. Sensor PH $=$ Mendeteksi Nilai $\mathrm{PH}$

6. Pompa EC = Pompa akan hidup apabila cairan EC pada ember air kurang

7. Pompa $\mathrm{PH}=$ Pompa akan hidup apabila cairan EC pada ember air kurang

8. Selang EC= Mengaliri cairan EC dari ember EC menuju ember air

9. Selang $\mathrm{PH}=$ Mengaliri cairan $\mathrm{PH}$ dari ember $\mathrm{PH}$ menuju ember air

10. Wadah $\mathrm{PH}=$ Sebagai penyimpanan cadangan cairan $\mathrm{PH}$

11. Wadah EC = Sebagai penyimpan cadangan cairan EC

12. Wadah Utama = Sebagai tempat percampuran air, ec, ph yang sudah siapuntuk tanaman.

13. Laptop = Sebagai server dan untuk menampilkan web monitoring.

Alur kerja dari gambar diatas ialah sensor EC dan $\mathrm{PH}$ mengambil nilai berupa angka yang didapat oleh kedua sensor. Kemudian data tersebut dikirim ke arduino dan ke database. Dari database data tersebut dikirim ke web monitoring untuk dibaca. Apabila setelah dibaca terdapat kekurangan kandungan EC atau PH maka arduino akan langsung mengirim perintah kepada relay untuk mengaliri arus voltase kepada masing-masing pompa sehingga pompa dapat mengaliri kandungan $\mathrm{EC}$ atau $\mathrm{PH}$ dengan menggunakan selang ke wadah utama.

\section{Kesimpulan}

Berdasarkan hasil penelitian yang dilakukan terhadap Sistem kontrol berbasis web pada aeroponiksystem dengan menerapkan konsep internet of things, maka dapat disimpulkan sebagai berikut :

1. Perancangan sistem kontrol pada aeroponiksystem sudah dapat di implementasikan dengan menerapkan konsep internet of things.

2. Data suhu, kelembapan, EC dan PH dapat disimpan di database.

3. Kondisi suhu, kelembapan, EC dan PH aeroponiksystem dapat dimonitor melalui web berdasarkan data yang ada didalam database.

\section{Daftar Pustaka}

[1] T. Indrawati and A. Anggriawan, "Peranan Komoditi Gambir Terhadap Perekonomian Kabupaten Lima Puluh Kota Provinsi Sumatera Barat," J. Ekon., vol. 21, no. 2, 2013, [Online]. Available:

https://media.neliti.com/media/publications/868 8-ID-peranan-komoditi-gambir-terhadapperekonomian-kabupaten-lima-puluh-kotaprovinsi.pdf.

[2] R. Y. Endra, A. Cucus, F. N. Affandi, and D. Hermawan, "Implementasi Sistem Kontrol Berbasis Web Pada Smart Room Dengan Menggunakan Konsep Internet Of Things," Explor. - J. Sist. Inf. dan Telemat. (Telekomunikasi, Multimed. Inform., vol. 10, no. 2, pp. 98-106, 2019, doi: http://dx.doi.org/10.36448/jsit.v10i2.1316.

[3] A. Cucus and M. S. Febrianti, "Implementation of Sensor Ph Meter, Ec Meter and Temperature on Smart Vertical Agriculture System.," ICETD 2017, pp. 446-452, 2017.

[4] A. Junaidi, "Internet Of Things, Sejarah, Teknologi Dan Penerapannya," J. Ilm. Teknol. Inf. Terap., 2015.

[5] A. AlShrouf, "Hydroponics, Aeroponic and Aquaponic as Compared with Conventional Farming," Am. Sci. Res. J. Eng. Technol. Sci., vol. 27, no. 1, pp. 247-255, 2017, [Online]. Available: https://asrjetsjournal.org/index.php/American_Sc ientific_Journal/article/view/2543.

[6] I. S. Roidah, "Pemanfaatan Lahan Dengan Menggunakan Sistem Hidroponik," J. Univ. Tulungagung Bonorowo, vol. 1, no. 2, 2014, [Online]. Available: http://jurnalunita.org/index.php/bonorowo/article/viewFile/ 14/11.

[7] S. Samuel and R. Muhammad, "Monitoring dan Kontrol Sistem Penyemprotan Air untuk Budidaya Aeroponik Menggunakan NodeMCU ESP8266," J. Tek. ITS, vol. 7, no. 2, pp. A380-A385, 2018.

[8] T. Y. Arkhan Subari, Dista Yoel Tadeus, Heru Winarno, "Rancang Bangun Sistem Administrasi Kerja Praktek Dan Tugas Akhir Berbasis Web Menggunakan Framework Codeigniter," GEMA Teknol., vol. 19, no. 4, 2018, [Online]. Available: https://ejournal.undip.ac.id/index.php/gema_tekn ologi/article/download/19147/13322.

[9] Sugiyono, Metode Penelitian Kuantitatif Kualitatif dan R※D. Bandung: Alfabeta, 2014. 